\author{
ALEJANDRINA ESCUDERO \\ FACULTAD DE FILOSOFÍA Y LETRAS, UNAM
}

\title{
La ciudad posrevolucionaria en tres planos
}

Nuestra ciudad. Mía. Salvador Novo

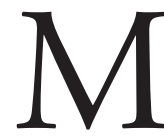

APAS y planos han SIDO una fuente destacada en la historiografía de la ciudad de México, ${ }^{\mathrm{I}}$ que permite conocer su pasado urbano al ofrecer pormenores de topografía, límites, traza, inventario de garitas, acequias, diques o albarradones, puentes, canales, plazas, paseos, jardines, calles, calzadas, panteones, servicios (emplazamiento de banquetas y pavimentos, apertura de calles, tendido de alumbrado, abastecimiento de agua, construcción de drenaje y desagüe), arquitectura, red ferroviaria y tranviaria, pueblos, haciendas y ranchos, colonias y fraccionamientos, y acciones militares, entre otros aspectos.

El espacio bidimensional que muestra información topográfica, geográfica, técnica, catastral, histórica, cultural, artística, turística, vial y edilicia se vale de un código y lenguaje común característico; sin embargo, al considerar mapas y planos como documentos para el estudio de la urbe, además de darles el tratamiento de cualquier fuente, habrá que plantearse respecto a ellos, entre otras cuestiones, el tipo a que corresponden (técnico, catastral, artístico o regulador), la índole del autor (agrimensor, alarife, topógrafo, ingeniero, arquitecto, pintor, dibujante o urbanista), su finalidad, la identidad de quien lo costea (patrocina-

I. Aunque hay una diferencia entre los términos "mapa" y "plano", aquí los usaremos indistintamente. 
dor), su circulación y su manera de representar el espacio. ${ }^{2}$ Este trabajo intentará un primer acercamiento a esas interrogantes, a partir de tres tipos de planos realizados entre 1929 y 1932: los catastrales producidos por el Departamento del Distrito Federal, un mapa artístico de la pintora Emily Edwards financiado por dos empresas privadas y un plano regulador del urbanista Carlos Contreras dibujado por Justino Fernández. Los tres se caracterizan por representar la ciudad de México y sus alrededores desde un plano vertical.

\section{Los planos y la ciudad}

A finales de la década de 1930, Justino Fernández y Manuel Toussaint señalaron cuatro periodos en la historia de la ciudad en función de sus planos: prehispánico, virreinal (desde la Conquista hasta mediados del siglo XIX), independiente (desde las Leyes de Reforma hasta I9IO) y contemporáneo (desde I9IO hasta finales de los años treinta del siglo pasado). ${ }^{3}$ Los realizados hasta mediados del siglo XIX han sido ampliamente conocidos y estudiados, pero los producidos durante los dos últimos periodos rara vez se han analizado pese a ser abundantes y variados. ${ }^{4}$

2. "Los mapas comparten muchos intereses comunes con el estudio del libro al exhibir su función textual en el mundo y ser 'sujetos de control bibliográfico, interpretación y análisis histórico...”, John Brian Harley, La nueva naturaleza de los mapas, México, Fondo de Cultura Económica, 2005, p. 62. Desde esta perspectiva, es amplia la bibliografía y encontramos estudios como el de David Buisseret (ed.), Envisioning the City. Six Studies in Urban Carthography, University of Chicago Press, I998; John Pinto, "Origins and Developments of the Iconographic City Plan", Journal of the Society of Architectural Historians, núm. 35, 1996, y David Buisseret, The Map's Makers Quest, Nueva York, Oxford University Press, 2003.

3. Manuel Toussaint, Justino Fernández y Federico Gómez de Orozco, Planos de la ciudad de México. Siglos XVI y XVII. Estudio histórico, urbanistico y bibliográfico. XVI Congreso Internacional de Planificación y de la Habitación, México, Cultura, 1938. Ethel Herrera y Concepción de Ita ofrecieron, igualmente, en 1982, una periodización de los planos que coincide también con la historia política y que abarca de I325 a 1933: 500 planos de la ciudad de México, México, Instituto Nacional de Antropología e Historia, 1982. Conviene hacer notar que los estudios sobre estos documentos gráficos terminan su periodización y estudio en la década de 1930.

4. Entre los coleccionistas y estudiosos de planos y mapas de la ciudad destacan Carlos de Sigüenza y Góngora, Lorenzo Boturini, Manuel Orozco y Berra, Antonio García Cubas, Leopoldo Batres, Manuel Olaguíbel, Ignacio Alcocer, Manuel Carrera Stampa, Jesús Galindo y Villa, Manuel Francisco Álvarez, José R. Benítez, Justino Fernández, Manuel Toussaint, Diego Angulo, Ola Apenes y, recientemente, Ethel Herrera y Sonia Lombardo. 


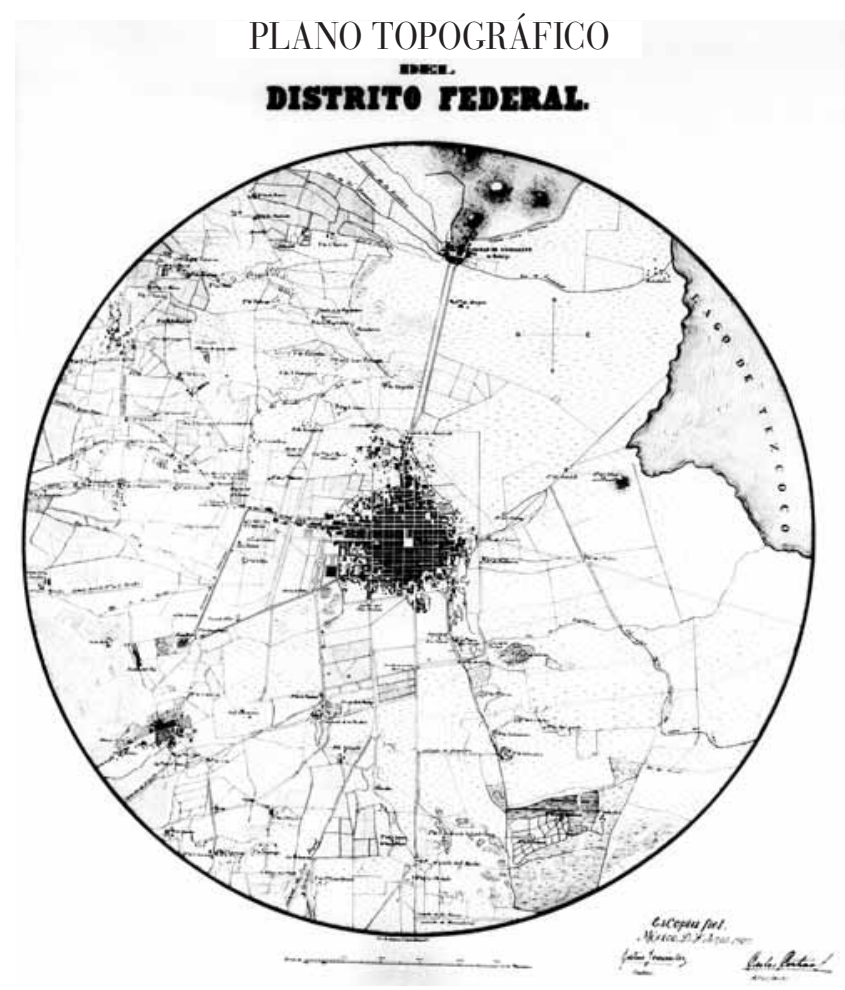

I. Justino Fernández, Plano topográfico del Distrito Federal, I927, copia fiel, Carlos Contreras, arquitecto. Archivo Carlos Contreras.

En el siglo XIX y las primeras tres décadas del Xx, además de los innumerables planos preparados por dependencias gubernamentales, se hicieron otros con fines comerciales y turísticos; entre ellos, revistieron gran importancia las guías que proliferaron ante la afluencia de viajeros y expedicionarios interesados ya en las riquezas del país o en la cultura prehispánica. Con el paso del tiempo, las guías de forasteros populares en el siglo XIX se convirtieron en guías de viajero, género que hasta hoy perdura y donde los planos y mapas constituyen un elemento sustancial.

A principios del siglo xx destacan publicaciones como la Guía de México. Interesantes estudios históricos, principales informes urbanos, nomenclatura antigua y moderna de las calles, plano a varias tintas de la ciudad, por el Dr. Carlos 
Barajas, profesor de la Universidad Nacional (1915) y la Guia Roji, que empezó a editarse en 1928 como una guía — un handbook- y no sólo como el plano que actualmente conocemos. Entre otras ediciones dedicadas al país y su capital se cuentan la Terry's Mexico: Handbook for Travelers, que se editó en 1909, 1923, 1927 y 1930, y la Guía y planos. Distrito Federal. Carreteras y caminos, de 1935, generosamente ilustradas con fotografías y planos de gran formato que se incluían doblados.

Para su venta, y al parecer con una amplia circulación, se hicieron hojas sueltas de pequeño o gran formato tipo cartel con diversas técnicas (grabado, fotograbado, zincografía, fotolitografía, litografía, dibujo a tinta y offset), impresas en México y en el extranjero; algunas "compañías litográficas y después tipográficas las reprodujeron, llegándose a establecer la costumbre de publicarlas anualmente, consignando las reformas y los cambios". 5 También se comercializaron litografías como las de Casimiro Castro y, después de la segunda mitad del siglo XIX, algunas casas comerciales obsequiaron a sus clientes trabajos en los que predominaron las vistas "a vuelo de pájaro", perfiles y maquetas. ${ }^{6}$

En la segunda mitad del siglo xix resultaron de suma importancia para el conocimiento del Distrito Federal los trabajos de geógrafos como Manuel Orozco y Berra y Antonio García Cubas, lo mismo que estudios técnicos como los relativos a las obras de desagüe de la cuenca de México publicados a inicios del siglo siguiente.

Mapas y planos de la ciudad también circularon particularmente durante el siglo $\mathrm{xx}$ en anuarios, almanaques, diccionarios, manuales y memorias; en ocasiones, cuando había congresos y encuentros de especialistas, se obsequiaban, ya fuera en hojas sueltas o incluidos en los programas de actividades. ${ }^{7}$

5. Sonia Lombardo, Atlas histórico de la ciudad de México, México, Cartón y Papel de México/ Consejo Nacional para la Cultura y las Artes-Instituto Nacional de Antropología e Historia, I996, vol. I, p. 34 .

6. Para David Buisseret hay cuatro maneras de representar la ciudad en un plano: vertical, a vuelo de pájaro, perfil y maqueta. Véase Envisioning the City..., op. cit., pp. IX-XII.

7. No sólo las guías incluían estos complementos; la celebración de algún congreso de especialistas significaba una oportunidad para imprimir algún plano o mapa y obsequiarlo, como el Plano oficial de la ciudad de México. Edición especial para el Consejo Superior del Gobierno del Distrito Federal, con motivo de la reunión del X Congreso Geológico Internacional. Septiembre de I906 y los del Congreso Nacional de Planeación (I930). 


\section{La ciudad posrevolucionaria}

Para evaluar la factura de los documentos gráficos aquí revisados convendrá tomar en cuenta algunos factores que determinaron la forma de representar la ciudad y el Distrito Federal y sus alrededores: la intención al trazarlos y ponerlos en circulación en el marco del cambio de régimen político-administrativo ocurrido a partir de 1929, la expansión de la mancha urbana y las innovaciones tecnológicas que revolucionaron el registro cartográfico de las ciudades.

Lo primero se refiere a la promulgación de la Ley Orgánica del Distrito y de los Territorios Federales del 3I de diciembre de I928, que dividió al Distrito Federal en un Departamento Central y trece delegaciones foráneas, para lo cual se dispusieron los siguientes cambios y ajustes de los antiguos municipios: el Departamento Central quedaba formado por las municipalidades de México, Tacuba, Tacubaya, Mixcoac y trece delegaciones: Guadalupe Hidalgo, Azcapotzalco, Iztacalco, General Anaya, Coyoacán, San Ángel, Magdalena Contreras, Cuajimalpa, Tlalpan, Iztapalapa, Xochimilco, Milpa Alta y Tláhuac. Asimismo, la ciudad de México se establecía como cabecera tanto del Departamento Central como, a la vez, del Distrito Federal, y como capital de la República. Entonces, planos y mapas tuvieron que adecuarse para marcar los límites de las delegaciones y del Departamento Central, según lo indicaba la mencionada ley. ${ }^{8}$ La emisión de planos del Distrito Federal, en particular los de carácter técnico, fue la más frecuente, y en ellos se mostraba la gran mancha central ligada con los asentamientos, ahora sedes delegacionales, por medio de grandes calzadas y por la red de tranvías. Por otra parte, los relacionados con el Departamento Central, referido a la ciudad de México, empezaron a eliminar la división en cuarteles.

\section{Hacia una gran metrópoli}

Otro factor importante fue la expansión de la mancha urbana ocurrida entre las dos últimas décadas del siglo XIX y las tres primeras del $\mathrm{xx},{ }^{9}$ al asentarse

8. Ley Orgánica del Distrito Federal y de los Territorios Federales, Obras Públicas. Órgano del Departamento del Distrito Federal, año I, vol. I, núm. 4, abril de I930, pp. 284-290.

9. Federico Fernández Christlieb propone periodos suficientemente largos para el estudio de la ciudad de México: "primero, la fundación y desarrollo de una ciudad prehispánica con características geométricas definidas; segundo, la ciudad trazada por los conquistadores en el 
"colonias" y fraccionamientos que empezaron a ligar la ciudad con los pueblos, ya entonces convertidos en delegaciones (como San Ángel y Tlalpan), o al flanquear calzadas (como Reforma y Tlalpan), debido a lo cual desaparecieron ranchos, haciendas, ejidos, ríos y canales. A algunas de esas colonias se las dotó de infraestructura de primer nivel, pero la mayoría de ellas se fraccionaron sin servicios básicos. ${ }^{\text {Io }}$

La traza virreinal se transformó con la demolición o cambio de uso de bienes eclesiásticos, lo que trajo la apertura de calles que afinaron su forma de damero. ${ }^{\text {II }}$ En la periferia, el trazo de algunos fraccionamientos adoptó una forma cerrada (elíptica) de acuerdo con su topografía (Las Lomas de Chapultepec) o con su diseño original (Hipódromo Condesa) con influencias extranjeras. ${ }^{\text {I2 }}$

Independientemente de la desigual dotación de infraestructura urbana y el crecimiento azaroso, se empezó a enfrentar y solucionar los problemas de una forma integral, es decir, considerando la ciudad de México y el Distrito Federal en relación con la cuenca de México. ${ }^{13}$ Entonces surgieron las primeras estrategias y estudios de planificación total. ${ }^{14}$ Se crearon organismos especializados y se promulgaron algunas leyes, como la ya mencionada Ley Orgánica del Distrito y la Ley de Planificación y Zonificación del Distrito Federal y Terri-

siglo XvI; tercero, la ciudad colonial que guarda su tejido central casi intacto hasta mediados del siglo xviII; cuarto, la ciudad neoclásica, y quinto, la ciudad de hoy en la que predomina la influencia estadounidense", en Europa y el urbanismo neoclásico en la ciudad de México. Antecedentes y esplendores, México, Universidad Nacional Autónoma de México/Plaza y Valdés (Temas Selectos de Geografía de México), 2000, p. I7. En la periodización de la ciudad neoclásica, el autor marca el periodo de expansión entre I877 y I9I I.

Io. "Colonias o suburbios y barrios nuevos, que se le han agregado en el curso de esta generación: sin redes de agua ni de drenaje, sin pavimentos ni banquetas, sin alumbrado público ni policía, sin mercados, escuelas ni templos, y con servicios de transportes casi nulos." Véase "Por qué y en qué extensión faltan los servicios de urbanización en el Distrito Federal. Informe presentado por el señor doctor José Manuel Puig Casauranc, jefe del Departamento del Distrito Federal, al Consejo Consultivo del Departamento Central”, Obras Públicas, op. cit., pp. 223-232.

II. En el Porfiriato, entre otras, la apertura de Cinco de Mayo y, sobre todo, las calles que llegan a desembocar en San Juan de Letrán; entre 1933 y 1934, se abrieron algunas otras del centro, como 20 de Noviembre, Palma, San Juan de Letrán, López y Aranda.

I2. Chapultepec Heights (Lomas) y la Hipódromo Condesa fueron anunciadas como ciudades-jardín, a la manera de las inglesas de Ebenezer Howard.

I3. En particular, las propuestas del urbanista Carlos Contreras entre I927 y 1938.

I4. Para examinar el tema de la ciudad como un todo, véase Federico Fernández Christlieb, "Mirar la ciudad”, Ciudades, México, Red Nacional de Investigación Urbana, núm. 3I, julioseptiembre de 1996. 


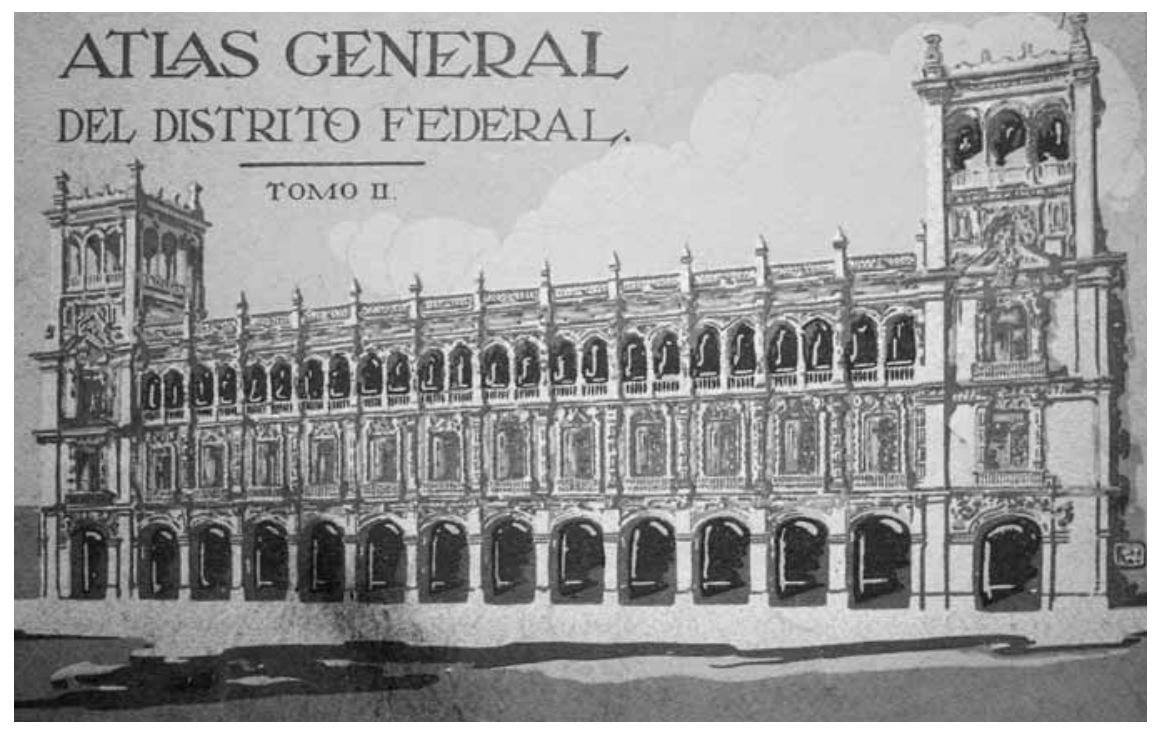

2. Portada del tomo in del Atlas general del Distrito Federal, México, Talleres Gráficos de la Nación, I930.

torios de la Baja California. Asimismo, se creó la Comisión de Planificación del Distrito Federal y se mantuvo un programa de obras públicas iniciado en la primera década del siglo $\mathrm{xx}$ y continuado hacia $1934 .{ }^{\text {Is }}$

Ciertamente, entre las dos últimas décadas del siglo XIX y las tres primeras del $\mathrm{xx}$ —periodo de poco más de medio siglo_-, se empieza a definir el perfil moderno de la ciudad, que al inicio de 1930 cuenta ya con una identidad urbana y arquitectónica, ${ }^{16}$ a pesar de que esto no resulta así según Manuel

I5. De este periodo véanse Informe que rinde el C. Jefe del Departamento del Distrito Federal, Lic. Aarón Sáenz, a la ciudad de México, 1934, s.p.i., y J.H. Penn, "Mexico City Spends 50,000,00o Pesos in its Public Works Program", San Antonio Express, San Antonio, Texas, Io de diciembre de 1933.

i6. Ya contaba con la mayoría de las colonias que se volverían tradicionales: al sur, por el eje de Insurgentes, la Del Valle, la Nápoles y la Guadalupe Inn; por el de Tlalpan, Obrera o Cuartelito, Hidalgo (después Doctores), Buenos Aires, Portales, Moderna, Postal, El Carmen y Toriello Guerra; hacia el poniente, Vallejo, Clavería, Santa Julia, Legaria, San Rafael, Santa María La Ribera, Juárez, Cuauhtémoc, San Miguel Chapultepec, Escandón, San Pedro de los Pinos, Mixcoac y Alta Vista; al norte, Ex Hipódromo de Peralvillo, Valle Gómez e Industrial; hacia el oriente, Romero Rubio, Balbuena y Magdalena Mixhuca, entre otras. En relación con la arquitectura, se había iniciado el movimiento moderno. Véase Esther Born, Modern Architecture 
Toussaint, quien afirma lo siguiente: "Un estudio especial debe hacerse del periodo comprendido entre 1857 y nuestros días, pues desde entonces viene a ser México casi una nueva ciudad que pierde personalidad para afrancesarse y ayancarse [sic], sin plan definido; al despojarse de muchas de sus características" ${ }^{17} \mathrm{Si}$ bien en ese lapso la capital había perdido algunos rasgos coloniales y lacustres, además de crecer de manera desordenada, había cierta estabilidad en su desarrollo, pues sus singulares asentamientos (colonias y fraccionamientos) y su amplia red circulatoria le confirieron una identidad urbana reconocida a lo largo del siglo $\mathrm{xx}^{18}$

Ese intervalo en la historia de la ciudad de México y el Distrito Federal, que va de la traza virreinal a la influencia francesa en el Porfiriato y, posteriormente, a la "yanki", 19 no es sino una larga transición a una urbe moderna con grandes avenidas asfaltadas que la cruzan, ${ }^{20}$ un extendido y eficiente sistema de ferrocarriles, primero, y de tranvías más tarde, a lo que siguió el tendido de alumbrado público, el incremento en la circulación de automóviles y camiones, la ramificación de los servicios públicos, el arranque de la arquitectura moderna mexicana y el surgimiento de un nuevo concepto de la relación entre la ciudad y el jefe del Departamento del Distrito Federal, además de otros factores. ${ }^{21} \mathrm{Y}$

in Mexico, Nueva York, Morrow, 1937, estudio que dio a conocer la producción edilicia de la ciudad durante las décadas de 1920 y 1930.

17. Hay que tomar en cuenta que su estudio se publicó a finales de 1930. Véase Toussaint et al., op. cit., p. I6.

I8. A lo largo de su historia la ciudad de México ha tenido varias identidades; con ello quiero decir rasgos que la han caracterizado en diferentes épocas.

I9. Probablemente Toussaint se refiera a las propuestas urbanísticas de Carlos Contreras, quien trajo a nuestro país las ideas del American City Planning y trazó la primera main street de la ciudad, que sería San Juan de Letrán.

20. Se le dio gran importancia a la circulación: a cargo del Departamento Central y de la Secretaría de Comunicaciones y Obras Públicas, hubo un movimiento importante para abrir, ampliar y prolongar calles y calzadas y empezaron a asfaltarse miles de kilómetros gracias al empuje de los tranvías eléctricos y el automóvil. Entre I9I9 y I928, por varios rumbos de la ciudad hubo un paulatino e incesante trabajo. En las memorias del Ayuntamiento de 1925, I926 y 1927 se detallan las obras de pavimentación (en I926: $178240 \mathrm{~m}^{2}$ ) y arreglo de calles; asimismo, los trabajos para prolongar, ampliar, abrir y alinear calles por toda la ciudad. Se dice que el taller de dibujo preparó un Plano general de la ciudad de México a escala I: I5 0oo, donde se indicaban los proyectos de ampliación y prolongación de calles para perfeccionar la traza de la capital. Véase Memoria 1926. Ayuntamiento Constitucional de México, México, Departamento de Publicidad, 1928.

2I. Del primer jefe del Departamento del Distrito Federal, José Manuel Puig Casauranc, empezó a circular el apotegma "Gobernar a la ciudad es servirla", que Aarón Sáenz hizo suyo luego. 
lo más importante: el afán de dotar a esa capital de una infraestructura urbana integral y de solucionar sus problemas en conjunto.

\section{Tecnología y cartografia}

Un ingrediente que modificó las representaciones de la ciudad de México y del Distrito Federal lo constituyeron los avances tecnológicos en materia de registro del espacio y de medición de la geografía urbana. En la década de I920, el perfeccionamiento de la fotografía aérea causó un efecto determinante en la factura de planos y mapas. ${ }^{22}$ En México, el Departamento de Aeronáutica Militar de la Secretaría de Guerra y Marina se especializó en ese tipo de tomas y con el tiempo las demandas empezaron a ser cubiertas por empresas especializadas. ${ }^{23}$ Respecto a este género fotográfico, Toussaint comenta: "Los cambios tecnológicos alcanzaron mayor precisión y las representaciones de la ciudad pasaron de imágenes pictóricas de vistas panorámicas a planos exactísimos en los cuales las medidas y las ubicaciones se corresponden proporcionalmente con las de los espacios reales". ${ }^{24}$

No sólo se pensaba en la exactitud del registro aéreo, sino también en la seguridad de que estas fotografías consignaran "inequívocamente" la morfología de cualquier espacio. Toussaint tiene razón al suponer que se pasa de una cartografía pictórica y empírica a otra "más científica". Si bien las fotografías aéreas horizontales permiten un registro útil para los proyectos de urbanización, en las aéreas oblicuas hay una mirada sesgada en perspectiva muy ligada con las vistas a vuelo de pájaro que resultaban muy atractivas desde el punto

22. El registro aéreo transformó completamente la cartografía y se convirtió en un elemento sustancial en su desarrollo. En I921, la Fairchild Aerial Camera Corporation preparó el mapa aéreo de Manhattan. Este enorme plano se hizo al reunir secuencias de fotografías verticales que creaban un efecto estereoscópico y ofrecían así un mosaico con la vista completa de la ciudad. Buisseret, The Map's Makers, op. cit., p. I6. Sobre su aplicación en México, véanse F. Antúnez Echegaray, "La foto-topografía y sus aplicaciones prácticas", Planificación, t. I, núm. 5, enero de 1928, y Alejandrina Escudero, "La fotografía aérea y la planificación de la ciudad de México, 1927-1938”, en Imagen e investigación social, México, Instituto Mora, 2005.

23. El urbanista Carlos Contreras trabajó en los últimos años de la década de 1920 con la Fairchild American Photo Aerial Survey. En los documentos oficiales de la compañía Aerofoto se dice que se fundó en 1936; sin embargo, encontramos fotografías aéreas de dicha empresa publicadas desde I933.

24. Toussaint et al., op. cit. 
de vista estético. Por lo mismo, éstas circularon en periódicos, revistas y tarjetas postales.

En la década de 1920 empezaron a levantarse planos de varios tipos por medio de fotografías a escala tomadas desde un aeroplano del Distrito Federal, y entre I9I9 y toda la década de 1920 ya se usaban y circulaban comúnmente. ${ }^{25}$

Además, este género fotográfico ofreció la posibilidad de elaborar mapas o mosaicos aéreos; los primeros creados en la República mexicana fueron los del puerto de Veracruz y del Distrito Federal, producidos hacia 1929 por la Fairchild American Photo Aerial Survey en respuesta a un encargo de la entonces Secretaría de Comunicaciones y Obras Públicas.

En resumen, los planos aquí revisados dan fe de esa transformación de la mancha urbana y la triplicación de su tamaño; también mostrarán su nueva división político-administrativa, los trabajos de infraestructura, el alumbrado, la red tranviaria, la pavimentación, el saneamiento y, entre otras relativas a este último aspecto, las obras de desagüe. En cambio, los impresos en hoja suelta o tipo cartel con vistas aéreas, a vuelo de pájaro o a manera de maqueta mostrarán los edificios, paseos y "lugares notables de la ciudad". Durante el periodo que va de las Leyes de Reforma hasta finales de $1930,{ }^{26}$ se apreciará un cambio estructural de la urbe que rebasa el casco colonial, acarrea una gran modernización (infraestructura, red de comunicaciones y transportes y arquitectura) y, también, crea el germen de los problemas propios de las grandes metrópolis de los siglos xx y xxI.

25. Se publicaron en el Álbum de obras materiales hechas por el gobierno federal. 1920-1924 c0rrespondiente al cuatrienio de Álvaro Obregón; también se exhibieron en la primera Exposición de Planificación de Ciudades y Regiones de 1927, de la cual se dice esto: "La sección de fotografía aérea fue considerada por todos como de las más interesantes, ya que contaba con vistas aéreas de hermosas y diversas partes de la ciudad de México, de muchas ciudades del país y del extranjero". "La primera Exposición de Planificación de Ciudades y Regiones", Planificación, núm. 2, octubre de I928, p. 20. En la edición del Atlas general del Distrito Federal, se hizo un gran despliegue de fotografías aéreas del Distrito Federal.

26. Para conocer el tema de la modernización urbana en este periodo, véanse Mauricio Tenorio Trillo, "i9ro Mexico City: Space and Nation in the City of the Centenario", Journal of Latin American Studies, vol. 28, núm. I, 1996, pp. 75-104, y Gerardo Sánchez Ruiz, Planificación y urbanismo de la Revolución mexicana. Los sustentos de una nueva modernidad de la ciudad de México, I9I7-I940, México, Universidad Autónoma Metropolitana Azcapotzalco/Asamblea Legislativa del Distrito Federal, II Legislatura, 2002. 


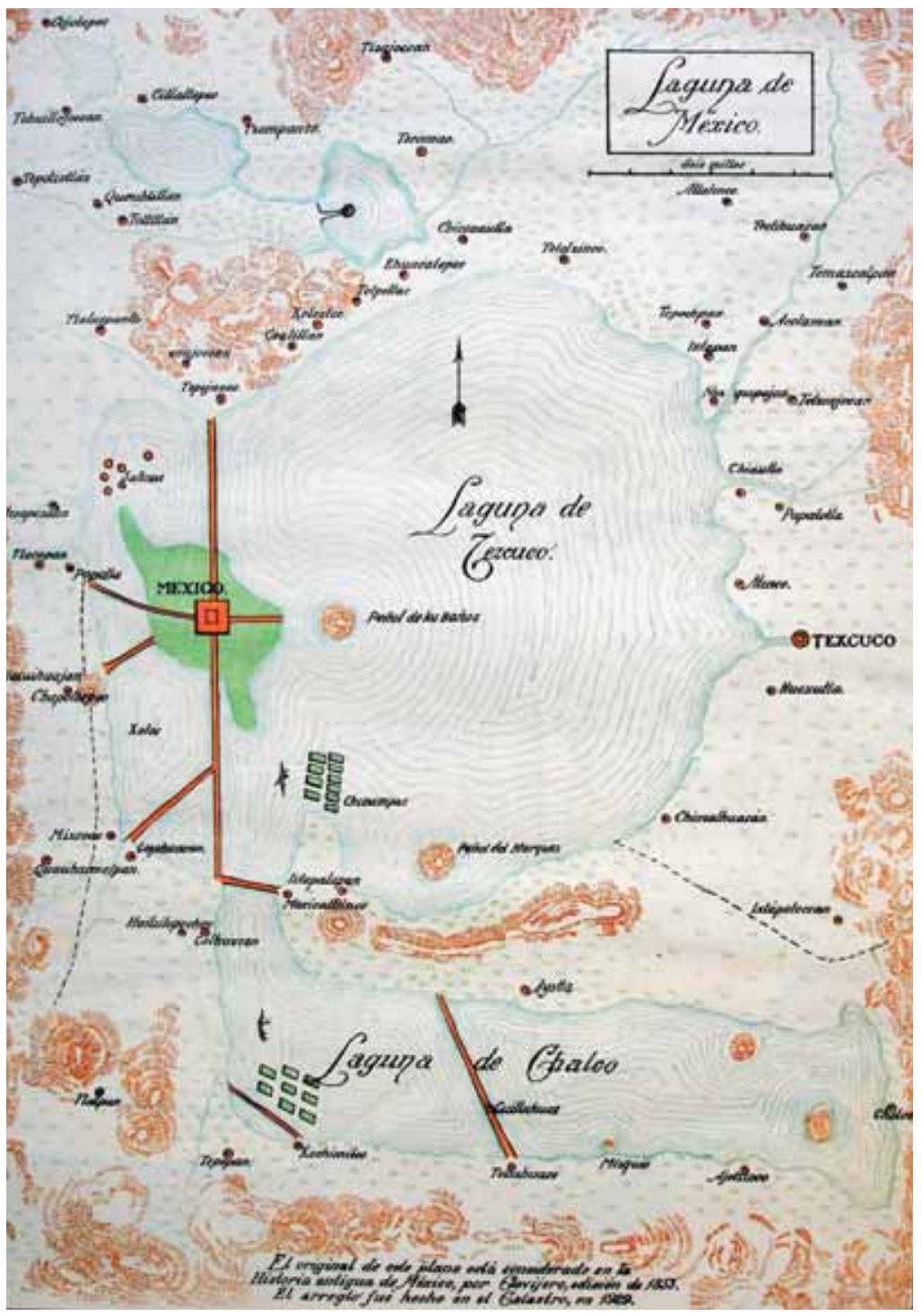

3. Laguna de México, reproducida en el Atlas general del Distrito Federal, México, Talleres Gráficos de la Nación, I930, s. n.; el original aparece en Historia antigua de México de Francisco Javier Clavijero, edición de I 853. 


\section{Plano catastral}

Los planos publicados en el Atlas general del Distrito Federal (1930), creado por encargo del entonces jefe del Departamento del Distrito Federal, José Manuel Puig Casauranc, se elaboraron en la Dirección de Catastro y su objetivo fue ofrecer un registro fidedigno del espacio urbano. Para esa edición se prepararon tres tipos de planos: el del Distrito Federal (escala r:50 ooo), el de la ciudad de México (escala i: Io o00) y los de las delegaciones (escala I: Io o00).

Editado en dos volúmenes, ${ }^{27}$ el Atlas reunía la más vasta y actualizada información de ese territorio hasta el momento. Aunque tiene mucho en común con las guías de viajeros que proporcionaban todos los datos posibles sobre la ciudad y sus alrededores, en realidad pretendía ofrecer una apología del estado que guardaban la ciudad de México y el Distrito Federal, avalada con documentos oficiales (relativos a censos, estadísticas, topografía y asuntos económicos, entre otros), bibliografía y un señalado despliegue gráfico. Otro rasgo que lo igualaba con las guías turísticas y comerciales se debía a su claro propósito de encomiar la capital: en

sus bellos edificios, sus anchurosas plazas, sus calles bien trazadas y pavimentadas, sus vastos jardines, sus magníficos servicios públicos y clima benigno, además de la belleza natural que le es peculiar, encontraremos la razón por la que es tan apreciada por turistas mexicanos y extranjeros que ven en ella un gran centro de cultura, comercio y urbanismo. ${ }^{28}$

En tamaño carta, el primer volumen del Atlas contiene datos sobre geografía, historia, organización administrativa y política, edificios públicos y comerciales, servicios, presupuestos, industrias, comercios, instituciones artísticas y científicas, entre otros. Está profusamente ilustrado con fotografías de tesoros urbanos (monumentos, edificios públicos y jardines, por mencionar algunos) y fotografías aéreas.

27. Se tenía considerado un tercer tomo dedicado "a tratar con amplitud y justicia el proceso del problema agrario del Distrito", pero, por razones que desconocemos, no se publicó. Atlas general del Distrito Federal. Geográfico, histórico, comercial, estadístico, agrario. Su descripción más completa y profusamente ilustrada con mapas, fotografias y gráficas. Esta obra se realizó por orden del doctor José Manuel Puig Casauranc, jefe del Departamento del Distrito Federal, en la Dirección del Catastro en 1929, México, Talleres Gráficos de la Nación, I930, vol. I, p. I4.

28. Ibidem, p. 44. 


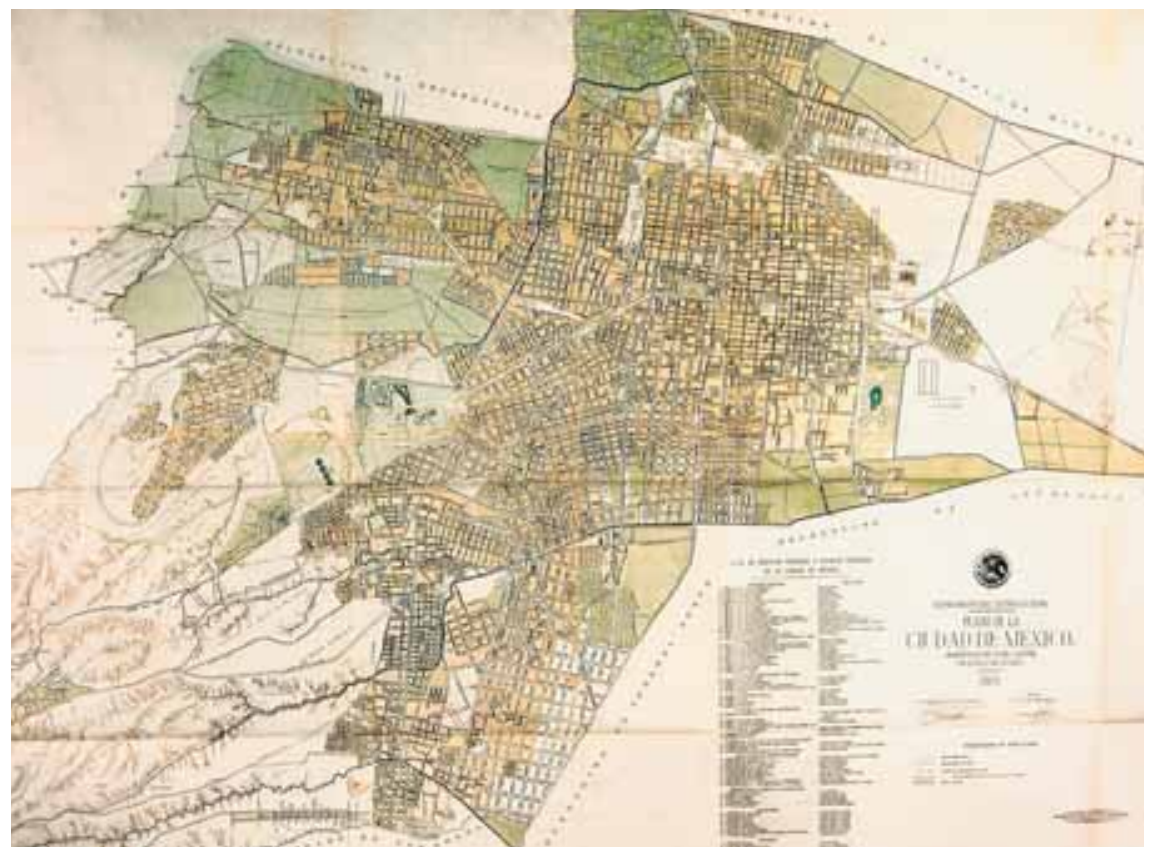

4. Plano de la ciudad de México, I929, escala i: I0 o00, publicado en el Atlas general del Distrito Federal, México, Talleres Gráficos de la Nación, I930, anexo doblado.

De gran formato y apaisado, el segundo tomo también incluye numerosas ilustraciones: fotografías aéreas, una lámina con glifos toponímicos y heráldica, y algunos planos antiguos redibujados por la Dirección de Catastro.

El Atlas general del Distrito Federal es la obra bibliográfica sobre el tema más ambiciosa del periodo; ${ }^{29}$ íntimamente relacionado con la nueva organización político-administrativa y su discurso, ubica a la ciudad de México y al Distrito Federal en un momento culminante de su desarrollo; este discurso, por un lado, se apoya en el pasado — historia, toponimia, heráldica, etc.—y, por otro, la compara con las más avanzadas metrópolis extranjeras. Respecto a esto último, un pasaje de la obra reza: "En la actualidad, la ciudad de México puede considerarse, respecto a pavimentos, en mejores condiciones que muchas de las

29. En I93 I se publicó la segunda edición de la obra por encargo del presidente de la República, Pascual Ortiz Rubio. 
capitales de Europa y posiblemente sea una de las mejores pavimentadas de América Latina”. 30

Los planos que incluyó la publicación fueron elaborados por la Dirección del Catastro del Departamento del Distrito Federal. El Plano del Distrito Federal (a color, de $93 \times$ I $33 \mathrm{~cm}$ ) señala la mancha urbana en rojo y, con signos convencionales, vías de ferrocarriles y tranvías, caminos, ríos y canales, acueductos, poblados y límites delegacionales. El Plano de la ciudad de México (a color, de $\mathrm{I} 30 \times \mathrm{I} 74 \mathrm{~cm}$ ) representa el Departamento Central, ${ }^{3 \mathrm{I}}$ sus límites, el trazo de calles y calzadas y "los edificios públicos y lugares notables de la ciudad". Los planos de las trece delegaciones (a color, de $33 \times 45 \mathrm{~cm}$ ) destacan la "zona urbana" de cada una; señalan el edificio delegacional y los parques, jardines, mercados, panteones, vías de tierra y agua, barrios y accidentes geográficos del área (ríos y canales), además de indicar ponderativamente el tipo de pavimento que cubre sus arterias. De los planos delegacionales aparecen en el Atlas dos versiones; ambas muestran los elementos mencionados, pero en uno de ellos, en detalle, se muestran algunos de los servicios con que cuenta cada delegación: lámparas eléctricas y red de atarjeas y agua potable. Los textos del Atlas refuerzan lo indicado por los planos, como en este ejemplo: "Actualmente se considera a México como una de las ciudades del mundo mejor iluminadas, y con razón. El lector puede consultar el plano del Departamento Central en el segundo tomo de esta obra y podrá ver con toda claridad la distribución exacta de las lámparas del alumbrado". ${ }^{32}$

Los planos y las fotografías incluidos en el Atlas general del Distrito Federal fundamentan el discurso relativo a una nueva ciudad, comparable con las grandes metrópolis, y resultante de una evolución —su pasado.

30. Atlas, op. cit., t. I, p. I20.

31. "Los límites de la ciudad son, al norte, el camino de la marina y la calle de Santa Cruz Atenco, la delegación Azcapotzalco, los ríos Chico y Unido y la delegación de Guadalupe Hidalgo; al oriente, el cerro del Peñón y el puerto central aéreo; al sur, el río de la Piedad, la delegación Iztacalco, la calzada de Niño Perdido, la delegación de General Anaya, la Barranca del Muerto y la delegación de San Ángel, y, al poniente, el pueblo de Santa Fe, las Lomas de Chapultepec hasta la avenida de las Palmas, el rancho de Sotelo y los linderos con el Estado de México." Lombardo, op. cit., p. 482.

32. Atlas, op. cit., t. I, p. I20. Ese mismo año de I930, Puig Casauranc preparó un plano "en el que se muestran las deficiencias de los más mínimos servicios urbanos” del Distrito Federal. Véase Nuestra Ciudad, México, núm. 2, I930. 


\section{Mapa artístico}

El Mapa de la ciudad de México y sus alrededores. Hoy y ayer, publicado por la Compañía Mexicana de Luz y Fuerza Motriz y por la Compañía de Tranvías de México (1932), ${ }^{33}$ fue realizado por la pintora estadounidense Emily Edwards. Aunque a simple vista se trata de un mapa artístico a color, en él hallamos un entramado de tradiciones cartográficas, iconográficas y pictóricas, además de la representación de varios periodos históricos de la ciudad y de la red de trenes y tranvías.

Respecto al patrocinio y la circulación del documento, fue el empresario George Robert Graham Conway, presidente y director gerente de las empresas que lo costearon, quien encargó a la pintora que lo creara. El Departamento de Publicidad de la compañía de tranvías distribuyó una versión del Mapa de la ciudad de México en blanco y negro, acompañada de una especie de boletín de prensa. Ya coloreado y terminado aquél, creemos que fue ampliamente difundido, aunque no conocemos su tiraje.

En una nota publicada en el periódico Excélsior, se afirma que, "bajo los generosos auspicios de la poderosa empresa, la señorita Emily Edwards proyectó y editó el más bello, original y sugestivo de los mapas modernos que de la ciudad de México y sus alrededores hayan aparecido en los últimos tiempos". ${ }^{34}$

Además de empresario, Conway fue un reconocido bibliófilo y coleccionista de documentos coloniales mexicanos, gráficos (mapas y fotografías) y escritos, además de admirador de la cultura prehispánica mesoamericana. ${ }^{35} \mathrm{Se}$ interesó en publicar algunos documentos de los que encargaba la paleografía, traducía su contenido al inglés y preparaba la introducción y las notas, como el artículo "Antonio de Espejo, as a Familiar of the Mexican Inquisition, I572I578" (193I) y los libros Postrera voluntad y testamento de Hernando Cortés,

33. Jacqueline Romero Yescas, quien tiene un ejemplar de 1932, me lo dio a conocer y me permitió fotografiarlo para este trabajo. Agradezco aquí su generosidad.

34. "Hermoso plano de la ciudad de México hecho a la manera de los del siglo diez y seis", Excélsior, I7 de abril de I932, p. 8. Véanse también "Bello plano-códice de la metrópoli editado por la compañía de Tranvías de México", El Universal, i7 de abril de 1932, y "El mapa de la ciudad”, en Electra. Magazine de Luz y Fuerza y Tranvias. Órgano del Personal de las Compañias de Luz y Fuerza Motriz y de Tranvías de México, año vi, núm. 70, enero-febrero de 1932, pp. I5-17.

35. George Robert Graham Conway (I873-195I) nació en Estados Unidos. Antes de su llegada a nuestro país trabajó en la Biblioteca del Congreso; entre 1915 y I942, fue presidente, director, gerente y representante general de la Compañía Mexicana de Luz y Fuerza Motriz y de la Compañía de Tranvías de México. 


\section{I 8}

ALEJANDRINA ESCUDERO

marqués del Valle (1940) y La noche triste, documentos. Segura de la Frontera en Nueva España, año de MDXX (1943). Al parecer, Conway también se interesaba en manifestaciones de la cultura mexicana contemporánea, como lo prueba la presentación que preparó para el libro Ernesto García Cabral. A Mexican Cartoonist (1923).

Por su parte, Emily Edwards fue una destacada pintora, escritora e historiadora que residió diez años en la capital (I926-I936). Durante su estancia en ella, recopiló material sobre el muralismo mexicano, y Diego Rivera fue su mentor. A este artista, le dedicó en 1932 el libro Murales del Palacio de Cortés (sobre sus obras creadas en Cuernavaca) y también le preparó en 1934 la guía Murales de la ciudad de México. ${ }^{36}$ Por los testimonios, creemos que empezó el mapa en I93 I y lo terminó a principios de i932, por lo cual queda claro que, mientras lo pintaba, preparaba sus libros sobre muralismo.

Antes de ser coloreado, el mapa se publicó en la revista Electra y en los periódicos capitalinos Excélsior y El Universal; la revista informa así acerca de cierta metodología aplicada en su hechura:

El señor Conway, presidente de las compañías, que posee una interesante colección de estos mapas, quiso que la ciudad de México tuviera también el suyo. Al efecto contrató los servicios de la señora Emily Edwards Cantabrana, quien se ha especializado en esta clase de trabajos. Después de un año de minuciosas investigaciones, llevadas a cabo con verdadero entusiasmo, y de una labor meritoria, el mapa queda terminado. Ya está en manos del impresor para su reproducción en gran escala. Esta reproducción será hecha en colores y podemos augurar que será una verdadera obra artística. ${ }^{37}$

36. Emily Edwards (I888-1980) nació en San Antonio, Texas, y estudió en el Art Institute of Chicago. Curlee afirma que en 1926 elaboró un mapa histórico anotado de San Antonio con el fin de conseguir fondos para la San Antonio Conservation Society, que fundó junto con Rena Maverick Green. Ese mismo año conoció a Diego Rivera y se hicieron amigos, y también empezó su residencia de diez años (1926-1936) en nuestro país. En 1966, la pintora publicó el libro Painted Walls of Mexico, nada menos que con fotografías de Manuel Álvarez Bravo. Véanse Kendall Curlee, www.tshaonline.org/handbook/online/articles/EE/fedı.html, y Teresita Quiroz Ávila, La ciudad de México: un guerrero águila. El mapa de Emily Edwards, México, Universidad Autónoma Metropolitana Azcapotzalco, 2006.

37. "El mapa de la ciudad", Electra, op. cit. De la obra preparada por la pintora se hizo una edición litográfica en color, impresa por la American Book and Printing; se trata de una hoja suelta que mide $77.5 \times 93 \mathrm{~cm}$ y fue doblada y distribuida dentro de un sobre que reproduce un fragmento del plano y el nombre del mapa; las compañías patrocinadoras aparecen en él en inglés. La revisión de esta obra se basará en dicha litografía. 


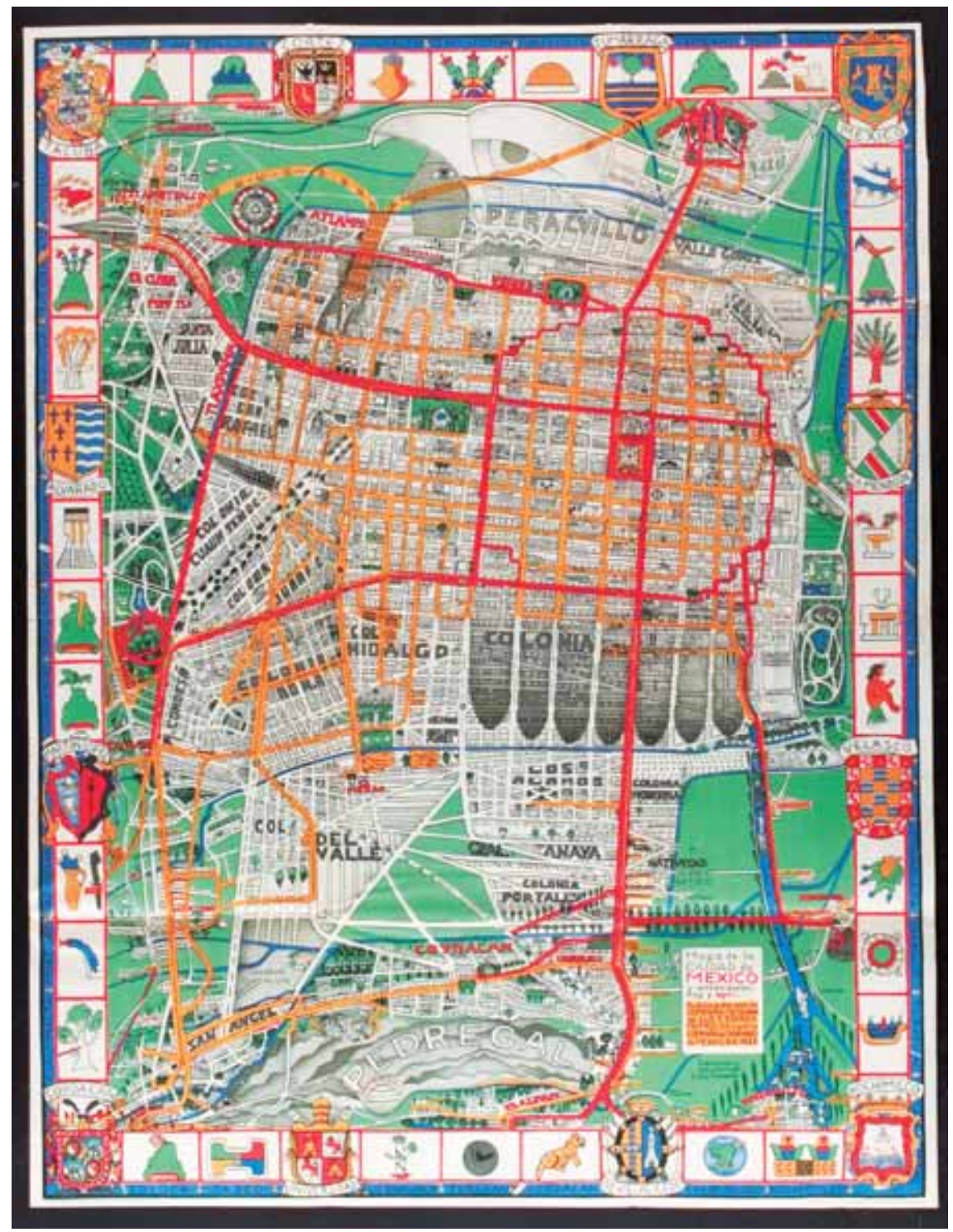

5. Emily Edwards, Mapa de la ciudad de México y sus alrededores. Hoy y ayer, 1932, litografía publicada por la Compañía Mexicana de Luz y Fuerza Motriz y por la Compañía de Tranvías de México, 1932. Archivo Jacqueline Romero Yescas. 


\section{La ciudad}

Los rasgos urbanos, históricos y arquitectónicos característicos de la ciudad en cada uno de sus periodos históricos, esto es: prehispánico, colonial, porfiriano, revolucionario y posrevolucionario, están representados.

Los elementos destacados de la ciudad prehispánica aparecen marcados con rojo y se refieren, principalmente, a sus calzadas, pueblos y barrios. De los alrededores se señalan sitios importantes del periodo, como Tenayuca y Tlalnepantla.

La traza colonial está marcada también con rojo. Los edificios religiosos situados fuera y dentro de ella aparecen finamente dibujados con sus rasgos arquitectónicos: cuerpos, torres, cúpulas y remates; también se incluyen edificios civiles.

En el Mapa de la ciudad de México y sus alrededores hay una clara lectura de la urbe del Porfiriato; por medio de tipografía sombreada en gris, se señalan las colonias fundadas en ese periodo. Asimismo aparecen las grandes obras públicas, como el Palacio Legislativo, el Teatro Nacional, Correos, el Banco de México y la Secretaría de Comunicaciones y Obras Públicas, entre otras.

De la ciudad posrevolucionaria aparecen las colonias recién creadas. A pesar de la enorme urbanización todavía se muestran grandes espacios verdes, algunos de los cuales se reservaban a la ganadería y la agricultura. También vemos que todavía hay elementos geográficos que la mayoría de nosotros ya no conocimos; por ejemplo, los ríos que atravesaban la ciudad de oriente a poniente, ubicados en el norte y en el sur. Asimismo, está perfectamente dibujado el Canal Nacional o Canal de la Viga, que desembocaba en Jamaica. Algunos hitos urbanos destacados también figuran ahí, entre ellos los parques México y Balbuena, y el Campo Aéreo. De la ciudad contemporánea, algunos espacios van acompańados de escenas de la vida cotidiana, como el avión en el campo aéreo, los jugadores de golf en el Country Club y las chinampas con turistas y un cantante en Xochimilco, ganado, etcétera.

\section{Tranvias y alumbrado}

El Mapa de la ciudad de México y sus alrededores cumple con su patrocinador al representar el sistema de tranvías (rutas, entronques y estaciones) y algunos elementos del alumbrado (líneas de alta tensión que vienen de El Oro y Necaxa y desembocan en Nonoalco, y la Estación de Luz y Fuerza en Tacubaya): las 


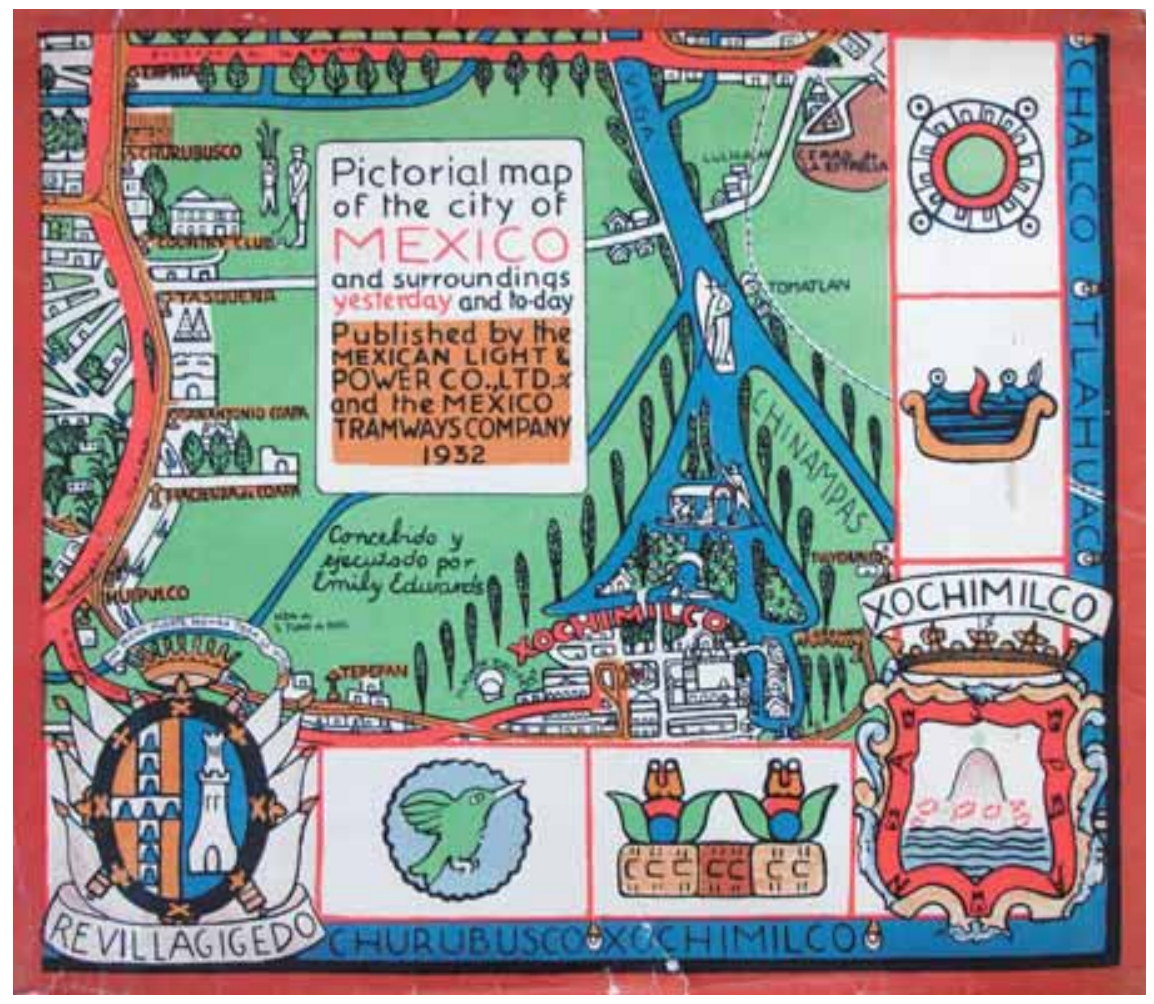

6. Portada de la carpeta que guarda el mapa. Nótese que el título aparece en inglés y el fragmento ahí reproducido es la zona suroriente del Distrito Federal. Archivo Jacqueline Romero Yescas.

líneas amarillas señalan las vías y las rojas las calzadas prehispánicas; asimismo, las salidas de los ferrocarriles foráneos: de Mexicalzingo a Zapotitlán, el de Río Frío, el interoceánico y el de San Rafael de Atlixco. Se puede apreciar que los tranvías se concentran en el Zócalo y de ahí arrancan hacia los diferentes rumbos de la ciudad. ${ }^{38}$

38. Entrevista con Héctor Lara (28 de marzo de 2006), arqueólogo industrial y cronista de transportes y movimientos tranviarios y ferrocarrileros del Distrito Federal de la Asociación de Cronistas del Distrito Federal y Zonas Conurbadas, quien hizo una minuciosa comparación con planos técnicos de las redes de tranvías de la época y llegó a la conclusión de que están fielmente señaladas en el mapa. Agradezco su generosa colaboración. En el artículo de la revista Electra antes mencionado, se afirma que los ingenieros de las dos compañías apoyaron a la pintora. 


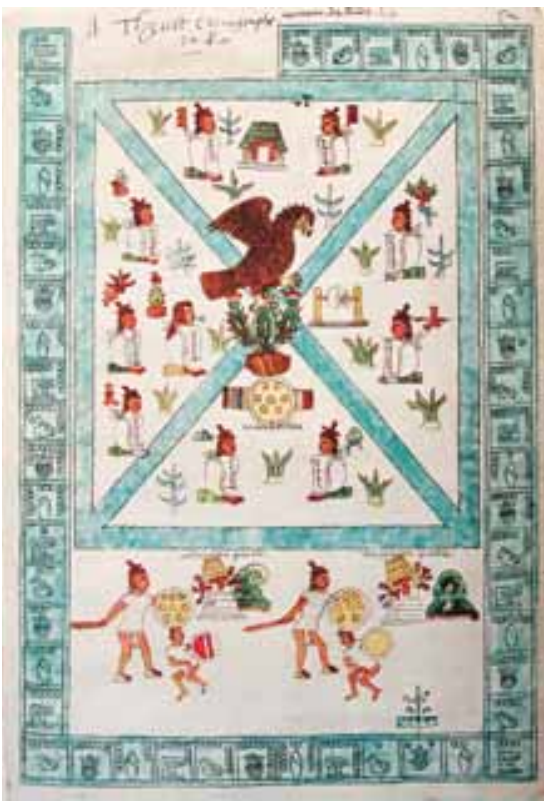

7. La fundación de Tenochtitlan, Códice mendocino, imagen tomada de Sonia Lombardo, Atlas histórico de la ciudad de México, México, Smurfit Cartón y Papel de México, I996, vol. I, p. 2 I 5.

\section{A manera de códice}

Hay una lectura que los patrocinadores difundieron acerca del Mapa de la ciudad de México y sus alrededores: en el boletín que el Departamento de Publicidad de la Compañía de Tranvías entregó a la prensa, se argumentaba que se había preparado "a la manera de un códice" y que, además, era un digno heredero del Mapa de Upsala, mejor conocido como Mapa de Santa Cruz, elaborado a la mitad del siglo xvi por la mano indígena. Las similitudes que el Mapa de la ciudad de México y sus alrededores tiene con el de Santa Cruz son el tamaño — casi idéntico-, el gran cuidado en el detalle, la representación de las poblaciones del Distrito Federal y de la cuenca de México con sus respectivos glifos toponímicos y, por último, los dibujos de escenas de la vida cotidiana de la época.

La composición del Mapa de la ciudad de México también tiene parecido con la lámina de La fundación de Tenochtitlan del Códice mendocino, pues en ambos

aparece en la parte central el águila sobre un nopal y sus lados dividida por una $\mathrm{X}$ formada por canales azul turquesa, una serie de señores, cada uno con su nombre 
pintado a la usanza indígena. Toda esta escena está enmarcada por una serie de cuadros azul turquesa con los símbolos de los años ácatl (caña), tochtli (conejo), calli (casa) y técatl (pedernal), los cuales están dando la fecha del acontecimiento central. En la parte inferior se observa una escena de guerra contra Culhuacán y Tenayuca. ${ }^{39}$

Si el Mapa de la ciudad de México y sus alrededores se lee del exterior al interior, en términos generales, se aprecia que lo enmarca una especie de marialuisa formada por una serie de glifos toponímicos y algunos elementos heráldicos. Esta sección, a su vez, aparece rodeada por una franja azul donde vienen los nombres de los glifos separados por una especie de foco, elemento también parecido a la representación de elementos acuáticos en algunos códices como el Nuttal.

Si antes nos habíamos referido a la fidelidad en la representación del sistema de tranvías, respecto a algunos elementos iconográficos puede decirse lo mismo. En el boletín de prensa referido se dice: "La colección de escudos y jeroglíficos, así como demás datos históricos, han sido minuciosamente revisados y aprobados por autoridades competentes del Museo Nacional". $4^{\circ}$

\section{Cuauhtémoc y la ciudad}

La figura de un guerrero águila, identificado como Cuauhtémoc, da forma a la mancha urbana. Uno de los artículos resalta la figura del guerrero águila que da sentido a la composición:

Enmarcado en los jeroglíficos de barrios y poblaciones indígenas, fielmente reproducidos de los códices y entre los que se intercalan los escudos de algunas ciudades y personajes eminentes durante la conquista y la colonia, aparece la arrogante y belicosa imagen de un caballero águila, el contorno de cuyo cuerpo lo diseñan las líneas de tranvías que atraviesan la capital. Perfila el clásico tocado que remata la cabeza del guerrero, el camino de Atzcapotzalco a Guadalupe Hidalgo y con otros elementos del trazo se complementa con sobriedad la figura del caballero que resulta altamente decorativa. ${ }^{4}$

39. Códices mexicanos. Artes del libro prehispánico, www.iconio.com/ABCD/F/sec_I8.htm

40. "El mapa de la ciudad", Electra, op. cit.

4I. "Hermoso plano...", Excélsior, op. cit. 
En la revista Electra también se hace referencia a esta figura:

El asunto [del mapa] ha sido tratado desde un punto de vista hondamente mexicano. Cuauhtémoc, el último rey azteca, el indómito guerrero, a quien hiciera sonreír el tormento, es el símbolo de la ciudad en esta representación. Su figura aparece esfumada en el "mapa en forma de códice", como en alguna ocasión le llamara la autora recordando un caballero águila a quien la ciudad moderna sirve de vestidura. ${ }^{42}$

El guerrero águila contiene la mayor parte de la mancha urbana a la manera de los mapas antropomorfos de la tradición cartográfica renacentista, que representan un espacio geográfico contenido en una figura humana. ${ }^{43}$ Así, Cuauhtémoc violenta, en cierta medida, el espacio urbano y le da forma. Al respecto, en la revista Electra se señala:

Para hacer caber lugares distantes y acopio tal de datos fue preciso apretujar por aquí y por allá, imponiéndose una verdadera serie de escalas; sin embargo el arreglo fue hecho con arte tan acabado que el conjunto en nada desmerece por esta circunstancia sino que forma un todo armonioso. ${ }^{44}$

Asimismo, la ciudad como un cuerpo se relaciona con las ideas urbanísticas vigentes, según las cuales la ciudad es un organismo vivo. ${ }^{45} \mathrm{El}$ arquitecto Carlos Contreras utiliza esta analogía al explicar que la ciudad de México ha crecido en forma desequilibrada:

No ha evolucionado como un organismo mediante la expansión correlativa de todas sus partes; de idéntica manera que el niño crece hasta la virilidad, no engordando simplemente, sino logrando que sus miembros, su cerebro y todos sus órganos se desarrollen en proporción para constituir un conjunto armonioso y racional. ${ }^{46}$

42. "El mapa de la ciudad", Electra, op. cit.

43. El mapa más conocido es el del continente europeo en la figura de una reina, del cual circularon varias versiones, entre ellas la de Matthias Quad (I587), Sebastián Münster (I588) y Hans Bünting ( 1588 ).

44. "El mapa de la ciudad", Electra, op.cit.

45. La idea de la ciudad como un organismo vivo no era nueva: se remonta a Platón y en diferentes épocas la han adoptado, tanto el urbanismo como la arquitectura y las ciencias sociales. Para conocer el tema de la visión organicista de la ciudad, véase Fernández Christlieb, "Mirar la ciudad", op. cit.

46. En esta analogía con el organismo se dice que las manzanas de casas y edificios constituyen su sistema óseo y muscular; las calles y arterias, su sistema circulatorio; los parques, espacios libres 
En este sentido, el urbanista se encargaría del cuidado de sus sistemas y funciones para que llevara una vida normal y saludable. Si el espacio urbano es visto aquí como un niño de crecimiento desequilibrado, la pintora da a la ciudad una forma equilibrada - el cuerpo humano-y simbólica.

Por otro lado, el análisis de la mancha urbana en algunos planos del Distrito Federal, en especial el de diciembre de 1930 de la compañía de tranvías, muestra que, debido a ese desarrollo desigual, la pintora no tuvo que hacer un gran esfuerzo para delinear al héroe mexica.

\section{Muralismo}

El Mapa de la ciudad de México y sus alrededores se relaciona también con el muralismo, ya que recuerda ciertas soluciones adoptadas por algunos seguidores de ese movimiento, en particular Diego Rivera; recupera varias etapas históricas, como lo había hecho este pintor por esos años al reunir en un solo espacio "la historia de México" en el cubo de la escalera de Palacio Nacional. También adopta la idea de la geografía como un cuerpo, cual lo hizo Rivera en los murales de Chapingo: La tierra fecunda, La tierra dormida y La tierra oprimida. ${ }^{47}$ De los murales del Palacio de Cortés en Cuernavaca, donde el muralista representa escenas de la Conquista y los fragmentos Tormento de Cuaubtémoc y Muerte de Cuaubtémoc, Emily Edwards toma la figura del héroe mexica. Los dibujos de escenas de actualidad (avión, jugador de golf, niños en el aula y turistas en Xochimilco), ejecutados de un modo sintético, nos recuerdan al Diego Rivera ilustrador o las grisallas de su obra en Cuernavaca.

Así, la asociación de dos extranjeros, ambos admiradores y estudiosos de la cultura mexicana, ${ }^{48}$ logra uno de los más ambiciosos mapas artísticos de nuestra

y campos de juego, sus pulmones; las redes de drenaje y alcantarillado, su aparato digestivo y excretorio; las líneas de transmisión de energía eléctrica, telégrafos y teléfonos, su sistema nervioso y sensorial, y la universidad, escuelas e instituciones científicas, su cerebro. Véase Planificación, núm. I2, t. I, agosto de I928, p. 3.

47. La representación de un espacio geográfico como un cuerpo humano en el arte mexicano ha sido estudiada por Rita Eder. Véase "El sueño de la Malinche de Antonio Ruiz y María Magdalena: algunas afinidades", en Cuauhtémoc Medina (comp.), XXV Coloquio Internacional de Historia del Arte. La imagen política, México, Universidad Nacional Autónoma de México-Instituto de Investigaciones Estéticas, 2006, pp. 96-I 43.

48. En su New Guide to Mexico with Maps and Illustrations (1946), Frances Toor publicó el Plano de la ciudad de México "basado sustancialmente en el de Emily Edwards". Véase Manuel 
capital, ${ }^{49}$ relacionado con el nacionalismo de la época, porque en él se recurre al pasado para hacer un documento "a la manera de códice", donde Cuauhtémoc, alegóricamente, representa la moderna ciudad posrevolucionaria.

Ante el Mapa de la ciudad de México y sus alrededores. Hoy y ayer (1932), de la texana Emily Edwards, replanteamos las cuestiones sobre el porqué y el cómo de su hechura, la manera en que representa a la ciudad y su patrocinio. Respecto a su factura, ¿qué predomina: el códice o el mural?, ¿por qué Cuauhtémoc es el símbolo de la ciudad?, ¿en qué grado las inclinaciones culturales de un empresario-bibliófilo admirador y estudioso de las culturas del pasado mexicano definieron su factura?, ¿̇se trata de un mapa más para su colección?

Si hemos de ver las relaciones y diferencias de esta obra con los trabajos que circularon en la época, se asemeja al Atlas de Puig al incluir toponimia, heráldica y planos antiguos de la ciudad. Respecto a las diferencias, las guías oficiales de la compañía de tranvías dirigidas al usuario tenían un formato de pocket book, pero el de la pintora alcanza el mismo tamaño de los planos técnicos de la compañía, como el de 1930, Mexico Tramways Co. The Mexican Light \& Power Co. Plan of Mexico City \& Suburbs. El mapa artístico a primera vista no resuelve las dudas del ingeniero, conductor o viajero urbano, pero sí lo induce a enmarcarlo y colgarlo en la sala de su casa o en una oficina..$^{\circ}$ En este sentido, habríamos de ligarlo con los planos de finales del siglo XIX y principios del xx patrocinados por compañías privadas que los distribuían entre sus clientes como obsequio, como la Vista de pájaro de la ciudad de México, I890, de gran formato (IO4 $\times 53 \mathrm{~cm}$ ), regalo de la Antigua Droguería de La Palma. Carlos Félix y Cía., hecho por J. Wellge e impreso por la American Publishing de Milwaukee.

Carrera Stampa, "Planos de la ciudad de México", Boletín de la Sociedad Mexicana de Geografía y Estadística, t. LXVII, núms. 2-3, marzo-junio de I949, p. 403.

49. Este mapa "artístico" no tiene comparación, por su complejidad, poder de síntesis y hechura, con otros que por esos años se hicieron en nuestro país, entre ellos el de Taxco (I930) de Roberto Montenegro y los de Taxco, Pátzcuaro, Morelia, Uruapan y Chapultepec realizados por Justino Fernández entre 1934 y 1937.

50. Las primeras guías de tranvías eran ediciones tipo pocket book - para el fácil manejo del viajero-, con ilustraciones de primera calidad; incluían horarios, kilometrajes, rutas y tarifas. Entre ellas figuran El Indispensable. Guia de los tranvias con todas las calles que recorren y transversales, de Emilio Galindo, publicada en 1913, y Guía oficial del Sistema de Tranvias de México, editada por la misma compañía en I922. El plano de 1930 al que nos referimos se reservaba para trabajadores, ingenieros y empresarios. 


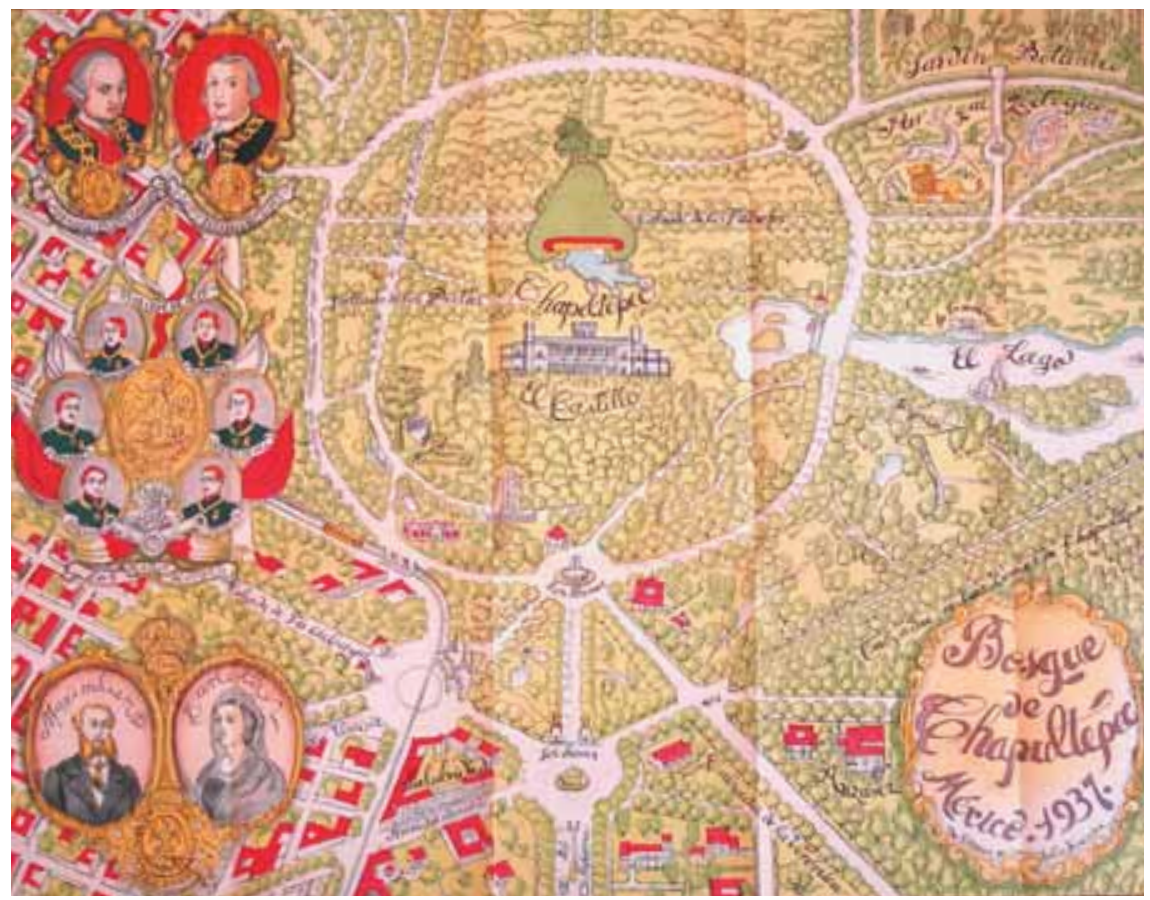

8. Justino Fernández, Bosque de Chapultepec, 1937, incluido en Alfonso Teja Zabre, Chapultepec: guía histórica y descriptiva con un plano pictórico del Bosque, México, Secretaría de Hacienda y Crédito Público, 1938, anexo doblado. Cortesía de Ramón Aureliano.

\section{Plano regulador}

El plano que se revisará en este apartado se incluyó en la publicación titulada Plano regulador del Distrito Federal, ${ }^{1933}$, del urbanista Carlos Contreras, ${ }^{\text {I }}$ con el nombre de "Estudio preliminar 1932". Antes de emprender la tarea de examinarlo, es necesario aclarar por qué se trata de un "plano regulador". En

51. Carlos Contreras (Aguascalientes, I892-ciudad de México, 1970) realizó sus estudios en la ciudad de Nueva York, egresó como arquitecto de la Columbia University en I92I, donde fue maestro hasta 1925 , año en que vino a radicar a la capital del país, e inició un movimiento para planificar la República mexicana y sus ciudades. 
principio, el urbanista lo describía así: "Folleto de 50 páginas con numerosos esquemas y un Estudio preliminar del Plano en la escala de i:Io 0oo".52

Al tanto de las recientes experiencias y de los avances de la disciplina urbanística — por su formación y estancia en Estados Unidos y la cercanía con personajes que, durante la última década del siglo XIX y las dos primeras del xx, realizaron los proyectos adscritos al llamado movimiento American City Planning_, 53 Contreras quiso adaptarlos a la realidad mexicana, en particular al Distrito Federal en el contexto de la cuenca de México.

Para ubicar el Plano regulador del Distrito Federal por su intención, habremos de remontarnos a algunos trabajos paradigmáticos de Estados Unidos, sobre todo al Plano de Chicago, de Daniel H. Burnham y Edward H. Bennet, volumen publicado en 1909 que combinaba textos con dibujos, pinturas, mapas, diagramas y planos, y que incluía un apéndice sobre ciertos aspectos legales. ${ }^{54}$ Desde una perspectiva histórica, los textos daban cuenta de las ideas de vanguardia de la planeación urbana estadounidense y el material gráfico ofrecía imágenes poderosas de un ideal de ciudad.

Otro proyecto que el mexicano conoció de cerca fue el Regional Plan of New York and Its Environs (Plano regional de Nueva York y sus alrededores), resultado de un minucioso estudio del espacio, la economía y la sociedad de la región, para el que él mismo preparó una serie de planos y dibujos. Esta labor tomó cinco años (I92I-1926) al Comité del Regional Plan of New York, que editó la obra en varios volúmenes monográficos. ${ }^{55}$

52. Carlos Contreras, Plano regulador del Distrito Federal, 1933, México, Talleres Linotipográficos de la Penitenciaría del Distrito Federal. El plano que aquí revisamos se llama "El Plano regulador del D. F. Estudio preliminar. I932. Escala I: Io ooo. Carlos Contreras, arquitecto”, mide $64 \times 47$ $\mathrm{cm}$ y se incluye doblado en esa publicación.

53. Como presidente de la Conferencia Internacional de Planificación, George Ford argumentaba que hacia 1924 el movimiento de planificación en ese país incluía 48 estados: se trabajaba en 350 ciudades y villas, había 300 comisiones de planificación y los reglamentos de zonificación se aplicaban en 325 ciudades y poblaciones; asimismo, se habían creado poblaciones completamente nuevas. Excélsior, 2 I de junio de 1925. Véase el estudio del American City Planning desde una perspectiva semiótica en Katherine Kia Tehranian, Modernity, Space and Power. The American City in Discourse and Practice, Nueva Jersey, Hampton Press, 2000.

54. Véase Gerald A. Danzer, "The Plan of Chicago by Daniel H. Burnham and Edward H. Bennet: Cartographic and Historical Perspectives", en Buisseret (ed.), Envisioning the City..., op. cit.

55. Al parecer, se editó en diez tomos, de los que nosotros sólo conocemos los ocho primeros. Regional Plan of New York and Its Environs, Nueva York, 1927. Theodora Kimbal señaló en I923 que éste era el estudio regional más importante iniciado en ese momento en Estados Unidos. Manual on Information on City Planning and Zoning, Cambridge, Harvard University Press, 1923, p. I66. 
El objetivo general de este levantamiento fue estudiar el crecimiento, características y necesidades de las comunidades en esa región urbana, económica y socialmente relacionada con el puerto de Nueva York, y resumir y presentar los resultados en una forma que sirviera de guía para la preparación de un plan de acción que mostrara y asegurara el mejor desarrollo de toda la región. ${ }^{56}$

El plano regulador o plano comprensivo que permitiría guiar y controlar el desarrollo físico de las ciudades era el instrumento fundamental de la planificación, disciplina a la que, en el arranque del siglo xx, también se hacía referencia con los términos "urbanismo", "arte cívico", "town planning", "city planning" y "Städtebau".

De acuerdo con los argumentos de Edward M. Basset, el Regional Plan of New York and Its Environs

en realidad se refiere a esos elementos de la vida de la ciudad que pueden ser expresados en los mapas — calles, edificios, parques, ferrocarriles y puertos. Aunque la planificación de la ciudad tiene que tomar en consideración muchos elementos intangibles, sus recomendaciones deben ser concretas además de poder mostrarse en un mapa, y de estar acompañadas de un programa de control, legislación y finanzas que permitan que las propuestas del mapa, gradualmente, se concreten en el terreno. Este plano o mapa "dinámico" no es fijo [...] sus líneas principales son fijas pero sus detalles cambian constantemente, conforme la ciudad crece y se transforma. ${ }^{57}$

El Plano regulador del Distrito Federal, 1933 era un ejemplar modesto a diferencia de los estadounidenses. A pesar de ello, tenía varias similitudes con ellos. En primer lugar, era prospectivo, es decir, formulaba una propuesta sobre lo

56. "The survey was made with the general object of examining the growth, characteristics, and needs of the communities in the whole urban region which is economically and socially related to the port of New York, and to summarize and present the results in a form that would afford guidance in the preparation of a plan so designed as to secure the best possible development of the whole Region." Ibidem, vol. I, p. XIII (trad. de la autora).

57. “...it deals actually with those elements of city life which can be expressed on maps — with streets and buildings and parks, with railroads and docks. While city planning must take into consideration many intangible facts, its recommendation must be concrete. They must be capable of being shown on a map, and they must be accompanied by a program of regulation, legislation, and finance that will make the map gradually come true on the ground. This 'dynamic' plan or map is not fixed once for all and incapable of change; its main outlines being fixed, its detail is constantly developing as the city grows and changes." Kimball, op. cit., p. 4 (trad. de la autora). 
que debía llegar a ser una ciudad o una región; ${ }^{58}$ los ideales eran los mismos: guiar, regular el espacio y llevar a cabo

un desarrollo coordinado, equitativo y armonioso de la región de la ciudad de México y sus alrededores que, de acuerdo con sus necesidades presentes y futuras, estimule de la mejor manera la salud, la seguridad, la moral, el orden, la conveniencia, la prosperidad y el bienestar general así como la eficiencia y la economía en el proceso de desarrollo. 59

Los planos reguladores de Chicago y Nueva York fueron patrocinados por profesionales y empresarios; en cambio, el Plano regulador del Distrito Federal fue financiado por miembros de la Asociación Nacional para la Planificación de la República Mexicana (ANPRM), se vendió en dos pesos y el producto de su venta se destinaría a un fondo de planificación manejado por ese organismo.

Otras semejanzas con los planos extranjeros se vinculan con la responsabilidad de la tarea. El urbanista mexicano recomendaba que un plano regulador debía estar en manos de "hombres de influencia y técnicos y competentes; debía exponerse y presentarse a la discusión, crítica y sugestiones de los habitantes de la región, antes de ser aprobado definitivamente". ${ }^{60}$ Según él, dependería de una comisión planificadora que coordinaría los intereses de diferentes sectores sociales, al igual que el de Nueva York.

En lo que se refiere a su circulación, el Plano de Chicago fue preparado para exhibir láminas y dibujos en forma independiente; por su parte, Frederic A. Delano, último responsable del Regional Plan of New York and Its Environs, comentaba que ese trabajo iba dirigido a cualquier habitante de la región que quisiera entender aspectos físicos, económicos y sociales del lugar. ${ }^{61}$ En este sentido, Contreras sugería construir un museo para exhibir las propuestas de planificación.

Respecto a su circulación, el Plano regulador del Distrito Federal al parecer sólo fue conocido por profesionales y funcionarios. No fue tomado en cuenta en esos momentos, aunque no hay duda de que este y otros proyectos de Con-

58. Para Contreras, un puerto, una ciudad, una municipalidad, un estado y la misma República mexicana debían tener un plano regulador para su desarrollo ordenado y armonioso.

59. “¿Comisión o Departamento de Planificación del Distrito Federal?”, Planificación, núm. I3, t. I, I928, p. I7.

6o. Ibidem, p. I4.

6I. Frederic A. Delano, presidente del Comité del Regional Plan of New York and Its Environs, en Regional Survey of New York and Its Environs, vol. I, p. v. 


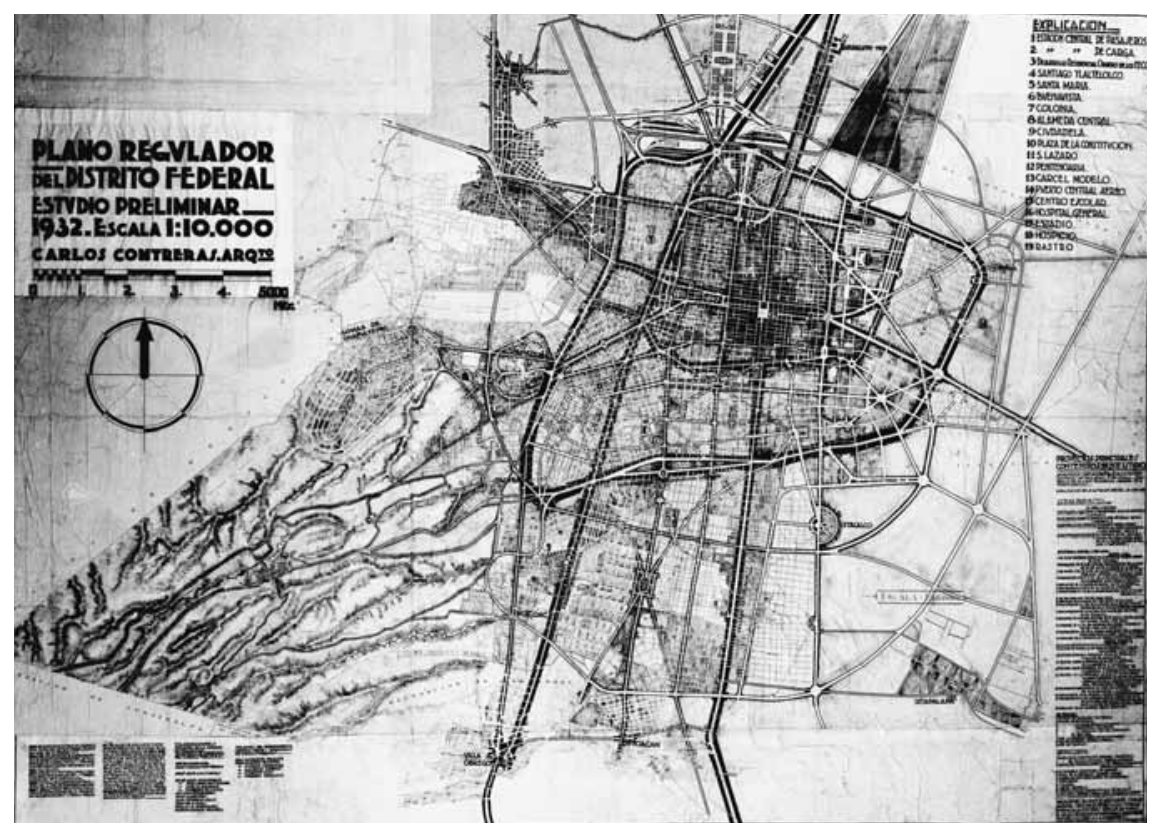

9. Plano regulador del Distrito Federal, "Estudio preliminar I932", escala I: Io ooo, Carlos Contreras arquitecto. Archivo Carlos Contreras.

treras se llevaron a cabo con escasas modificaciones y actualizaciones a lo largo del siglo Xx.

La idea de que la planificación era una inversión capaz de traer beneficios tanto a la comunidad como a los mismos inversionistas también fue adoptada por Contreras, aunque de hecho éste buscó el apoyo del gobierno para poner en marcha un trabajo de semejante naturaleza. Para ello creó dentro de la Secretaría de Comunicaciones y Obras Públicas (scop) la Comisión de Planeación, que él dirigió entre 1929 y 1932 y en donde preparó los primeros planes nacionales para crear u ordenar ciudades, puertos y el Distrito Federal. También impulsó el establecimiento de la Comisión de Planificación del Distrito Federal en 1933, y fue asesor suyo cuando la presidía Aarón Sáenz, jefe del Departamento del Distrito Federal (DDF), y cuando el secretario era Alberto J. Pani, también secretario de Hacienda.

Los estudios que Contreras realizó entre 1929 y 1932 en la SCOP se ven reflejados en su Plano regulador del Distrito Federal, edición que, al igual que 
las extranjeras, combinaba textos y planos. En los primeros trataba, de modo general, aspectos urbanos: población, zonificación, sistema vial y medios de transporte (ferrocarriles, tranvías, automóviles y camiones), sistemas de parques, jardines, campos de juego, estadios, reservas forestales, cementerios, parques conmemorativos y vías-parque, servicios municipales, casas habitación, recreación, arquitectura, financiamiento y legislación; todos ellos temas que en el Regional Plan of New York and Its Environs se desarrollaban en varios volúmenes, mientras que el mexicano los abordaba en pocas páginas, ya que lo hacía en apenas unos preliminares; su idea era que una comisión planificadora del Distrito Federal autorizara los estudios básicos de conjunto. ${ }^{62}$ Así, el Plano regulador de 1933 asentaba sólo los lineamientos para un desarrollo posterior.

El "Estudio preliminar" de 1932 incluido en el Plano regulador del Distrito Federal fue la pieza fundamental del proyecto de Contreras sobre la planificación de ese espacio, en el que desarrollaba un estudio de traza con énfasis en los sistemas de vialidad y transporte.

Hechos neurálgicos, como se ha visto, eran la expansión y el desorden urbanos; a decir de Contreras, la ciudad había crecido como un organismo enfermo porque sus adiciones se habían producido al azar, de modo "muy semejante al procedimiento de engorda que castiga a la actividad del cuerpo y hace de la vida una carga más pesada". ${ }^{63}$ Estas adiciones sucesivas se yuxtaponían alrededor de la celdilla original.

Factores fundamentales para ordenar el espacio urbano fueron la unificación de la traza existente y el control de su crecimiento futuro; con tales fines, señalaba Contreras, se debían estudiar las tendencias que la ciudad había mostrado durante siglos:

En mi opinión debe respetarse el trazo original y tradicional de la ciudad de México: la traza de Cortés, con sus calles de norte a sur y de oriente a poniente, y debe respetarse el movimiento natural del trazo de las avenidas inclinadas de suroeste a noroeste ligándolas con las de norte a sur y las de oriente a poniente. ${ }^{64}$

62. Carlos Contreras, Plano regulador del Distrito Federal, 1933, México, Talleres Linotipográficos de la Penitenciaría del D.F., $c a$. 1933.

63. Raymund Unwin, "Distribución de una ciudad", Planificación, t. I, núm. 3, noviembre de 1927 , pp. 5-7.

64. Memorando relacionado con la prolongación de la avenida Chapultepec, de Balderas y Arcos de Belén a la Plaza de la Constitución, 8 de septiembre de 1937. Archivo Carlos Contreras. 
El urbanista quiso hacer de las dos ciudades (la antigua y la nueva) una sola, siguiendo el núcleo que formaba el primer cuadro, que estaría ceñido por dos anillos de circunvalación, uno interior y otro exterior, con la finalidad de que los transportes no cruzaran el núcleo central para cuidar la zona antigua, como lo declara aquí:

La zona monumental tradicional se debe preservar, creando a su alrededor un anillo de circunvalación de 200 pies de ancho y estableciendo un control de todos los edificios de esta área, uso, peso, volumen y arquitectura, los cuales deben armonizar con los mejores ejemplos conservados de la zona. ${ }^{65}$

Contreras tuvo cuidado de que su proyecto no afectara lo ya existente, pues consideraba que los planos de expansión urbana debían cuidar la transición entre el ayer, el hoy y el mañana. ${ }^{66}$ Ante un espacio ya construido, en el estudio preliminar sólo se aplican algunos remedios o paliativos: se aprovechan las prolongadas calzadas que se han ido afinando y se observan algunos criterios que guían todos los proyectos de planificación del Distrito Federal creados por Contreras, tales como éstos:

I. Debe conservarse y respetarse la traza original de la ciudad de México, limitándola con un marco de cuatro amplias avenidas. 2. Deben crearse circunvalaciones amplias -interior y exterior. 3. Deben crearse todas las vías-parques propuestas, que le darán una personalidad vigorosa a la ciudad de México. 4. Dentro del primer boulevard de circunvalación debe conservarse el trazo cuadriculado dominante y acentuar las avenidas principales Norte-Sur y Oriente-Poniente, ampliándolas gradualmente pero con generosidad técnica. ${ }^{67}$

El estudio preliminar ofrece una traza que une todas las partes del Distrito Federal y se anticipa a un crecimiento urbano de dos generaciones. Se pone especial cuidado en la circulación y un sistema de transporte unificado y efi-

65. "The central monumental archeological traditional zone should be preserved by creating around it a circular ring boulevard 200 feet in width and by controlling all buildings within this area as to use, weight, bulk and architecture which should harmonize with the best examples to be preserved within the zone", Carlos Contreras, "Plan Development of Mexico City", en Esther Born, The New Architecture in Mexico, Nueva York, Morrow, 1937, p. 4 (trad. de la autora).

66. Idem.

67. Carlos Contreras, La planificación de la ciudad de México, 1918-1938, México, XVI Congreso Internacional de Planificación y de la Habitación, I938, p. 29. 
ciente, basado en ferrocarriles con terminales de pasajeros y de carga, campos de aviación y tranvías. Las calzadas ya existentes y otras nuevas que se abrirían se anticipaban a los problemas de tránsito futuros, ya que la "corriente fácil del tráfico constituye la sangre de la comunidad". ${ }^{68}$

En su conjunto, el sistema de circulación vial propuesto en el estudio preliminar de 1932 unifica el Distrito Federal, es decir, ofrece un espacio indiferenciado para esta entidad tan heterogénea; ello significa que, si bien cada una de las delegaciones, todavía en el arranque de la década de I930, tenía características climáticas y topográficas propias, además de pueblos, rancherías, ejidos, ríos, canales y economía particulares, se integraría a un solo espacio. Así, las dos ciudades - la antigua y la moderna, la central y la suburbana - estarían unidas por una red de grandes avenidas, vías, parques, arterias nuevas y arterias "de ligas" (que sumaban un total de 24), dos anillos de circunvalación y numerosos parques que la cruzarían a lo largo y a lo ancho.

\section{La representación de la ciudad}

Los tres tipos de planos realizados entre 1929 y 1932: los del Atlas general del Distrito Federal —Plano del Distrito Federal, Plano de la ciudad de México y planos de las delegaciones-; el Mapa de la ciudad de México y sus alrededores. Hoy y ayer, de la pintora Emily Edwards, y el estudio preliminar incluido en el Plano regulador del Distrito Federal del urbanista Carlos Contreras ofrecen invaluable información sobre la ciudad. Respecto a las cuestiones planteadas en un principio, acerca de su factura, forma de distribución, tipo de patrocinador y propósitos, siguieron algunas tradiciones.

Sin embargo, la revisión de esos aspectos será limitada para un estudio cabal de la ciudad en el momento de su factura, que sólo se puede hacer cuando se leen en diálogo con otras fuentes contemporáneas (memorias de gobierno, informes, libros, anuarios, notas periodísticas y fotografías) y trabajos de artistas, historiadores, arquitectos y urbanistas, es decir, en su contexto, entendido como "un conjunto complejo de fuerzas interactivas, un diálogo con el texto" que resulta fundamental para las estrategias interpretativas ${ }^{69}$ y que ha de extenderse a las fuentes gráficas. Aquí sólo se revisaron las cuestiones ya dichas,

68. Idem.

69. Harley, op. cit., p. 64. 
aunque podemos avanzar en algunas ideas sobre el tema que me interesa: cómo se representa la ciudad.

El elemento representado y la preocupación contemporánea remiten al crecimiento desmedido del espacio urbano; los tres planos, a su manera, ciñen una mancha urbana en expansión, fenómeno que para el urbanista Edward $\mathrm{H}$. Bennet constituye un factor muy potente, una fuerza que nos afecta a todos, cuando explica que "Dondequiera que hay crecimiento hay fuerzas poderosas, necesitando solamente el ser dirigidas para producir magníficos resultados [...] un plano de ciudad debe ser una obra de arte, una cosa viva capaz de excitar y de unir el interés y el entusiasmo de todos". ${ }^{70}$

Los planos aquí analizados pretendieron despertar el interés por el problema urbano. Los catastrales o estatales no pueden desligarse del Atlas general del Distrito de 1930 y muestran una ciudad con una nueva estructura político-administrativa, una localidad en vías de convertirse en una gran metrópoli, como las europeas y estadounidenses, aunque anclada en el pasado. En el Mapa de la ciudad de México y sus alrededores. Hoy y ayer, de Edwards, se observa la intención de representar fielmente el sistema de tranvías y alumbrado, lo mismo que la ciudad en varios periodos históricos; sin embargo, resultó una obra artística de gran calidad, que reúne tradiciones culturales mexicanas y propone a Cuauhtémoc como su símbolo. Por su parte, Carlos Contreras quiso plantear una nueva traza con miras al futuro, con la colaboración de autoridades, profesionales y lo que hoy llamamos sociedad civil.

Los tres grupos de documentos organizan el espacio a su manera. Nada más convencional — desde una perspectiva cartográfica - que los catastrales hechos por el Departamento del Distrito Federal, interesados en mostrar los límites territoriales y la infraestructura de cada delegación. El del Departamento Central (ciudad de México), con trazo impecable, revela cómo el damero original se ha perdido. El mapa del Distrito Federal, alarmantemente en rojo, señala una mancha urbana indiferenciada.

Nada más equilibrado y sugerente que la ciudad contenida en el cuerpo de un guerrero prehispánico; la pintora estadounidense representa la ciudad y el Distrito Federal con elementos de carácter histórico, simbólico e iconográfico. Ciñe la mancha urbana, la figura del guerrero mexica; el sistema tranviario y las antiguas calzadas (en rojo, como "arterias") funcionan para subrayar la indumentaria; fuera de la figura de Cuauhtémoc destacan los verdes y, rodeando el 
rectángulo de glifos toponímicos, una franja azul, símbolo de lo que queda de un área lacustre, aunque en el interior se brinda un Canal Nacional muy atractivo, reproducido en el sobre en que se distribuyó el mapa.

La ciudad desbordada es contenida y comunicada en el estudio preliminar propuesto por el urbanista Contreras a la manera de un "diagrama noble y lógico"71 que guiará y regulará su crecimiento, aunque su autor es consciente de que la propuesta es sólo un paliativo.

Estos planos representan el presente, el pasado y el futuro del Distrito Federal. Los del Departamento del Distrito Federal corresponden al presente, en medio de una contradicción: se iguala a las grandes metrópolis del extranjero; sin embargo, no cuenta con la infraestructura urbana que abarque a la ciudad y las delegaciones. El de Emily Edwards se asocia con el pasado y ofrece una representación simbólica de la ciudad contemporánea. Para la ciudad del futuro el urbanista propone una guía.

Para finalizar, recordaremos que Toussaint censuraba, en la década de I930, la falta de "identidad" de la ciudad; sin embargo, las representaciones aquí revisadas, elaboradas en los primeros años de esa década, intentaron imprimírsela: ${ }^{72}$ el Atlas, una identidad europea; el mapa de Emily, la mexica, y el plano del urbanista, una "personalidad vigorosa" basada en un sistema circulatorio. \$

71. La idea del plano regulador como un "diagrama noble y lógico" se basa en Daniel H. Burnham, quien conminaba así: "Haced proyectos grandes; elevad vuestras miras, en esperanza y en trabajo, recordando que un diagrama noble y lógico, una vez grabado, no morirá nunca [...] Que vuestro lema sea el orden, y la belleza, vuestra guía”, Planificación, t. I, núm. I, septiembre de 1927.

72. Encontramos dos metáforas relativas a la forma y la expansión de la ciudad en la década de I920: la de un reportero que desde un avión ve un gran "pulpo sobre la superficie de un mar, verde como el Mediterráneo", cuya cabeza era su núcleo central, y la de un empresario que observa algo semejante a un vientre colosal que paulatinamente se añade a sí mismo terrenos con sus garras. Véase Alejandrina Escudero, "Las formas de la ciudad”, Arquitectura, núm. io, año 5, 2006. 